\title{
AHL, Ingmar, Humanistische Politik zwischen Reformation und Gegenreformation. Der Fürstenspiegel des Jakob Omphalius
}

Naïma Ghermani

\section{OpenEdition}

Édition électronique

URL : http://journals.openedition.org/ifha/729

DOI : $10.4000 /$ ifha.729

ISSN : 2198-8943

Éditeur

IFRA - Institut franco-allemand (sciences historiques et sociales)

Référence électronique

Naïma Ghermani, « AHL, Ingmar, Humanistische Politik zwischen Reformation und Gegenreformation. Der Fürstenspiegel des Jakob Omphalius », Revue de l'IFHA [En ligne], Date de recension, mis en ligne le 01 janvier 2006, consulté le 22 septembre 2020. URL : http://journals.openedition.org/ifha/729 ; DOI : https://doi.org/10.4000/ifha.729

Ce document a été généré automatiquement le 22 septembre 2020.

(CIFHA 


\title{
AHL, Ingmar, Humanistische Politik zwischen Reformation und Gegenreformation. Der Fürstenspiegel des Jakob Omphalius
}

\author{
Naïma Ghermani
}

1 Longtemps victime d'une puissante Ideengeschichte qui retraçait une histoire téléologique des idées politiques de l'époque moderne comme une longue marche continue vers l'Aufklärung, jalonnée d'auteurs phares, l'histoire de la pensée politique dans l'Empire allemand connaît, ces derniers années, un renouveau certain sous l'impulsion des travaux incontournables de Michael Stolleis et sous l'influence majeure de l'œuvre de Quentin Skinner. Cette reviviscence, cependant, avait négligé un genre considéré comme mineur et pourtant très populaire au XVIe s. : les miroirs de princes ou Fürstenspiegel. Si ces derniers ont été recensés et identifiés, très peu cependant ont été l'objet d'une recherche renouvelée, les arrachant au positivisme et à la paraphrase.

2 C'est chose faite avec l'ouvrage d'I.A. Ce livre, issu d'une thèse de doctorat menée sous la double et prestigieuse férule de Notker Hammerstein et de Michael Stolleis, bien que consacré à l'unique œuvre d'un juriste du XVIe s., Jacob Omphalius, renouvelle considérablement l'histoire de la pensée politique dans l'Empire au temps de la Réformation. L'ouvrage, au premier regard, n'offre guère de variation par rapport à une monographie classique. Il propose une biographie précise du juriste et du contexte politique avant d'analyser partie par partie son œuvre. Pourtant, on comprend dès la brillante introduction qu'on aura affaire à un travail plus ambitieux, à une véritable histoire sociale et politique de l'humanisme juridique dans une situation allemande marquée par l'éclatement religieux. I.A. se place dans la filiation de l'œuvre de Skinner qui suggérait de replacer les idées politiques dans leur contexte et de s'intéresser à l'histoire des langages politiques. Le choix d'Omphalius est pertinent à bien des égards : en marge du large courant des Fürstenspiegel qui se développent massivement dès les débuts de la Réformation, lorsque les bouleversements dans les territoires exigent de 
redéfinir le prince chrétien à l'aide d'un concept de politica christiana, Omphalius est un des rares à introduire, en sus d'une énumération attendue des vertus du prince, une réflexion juridique sur la potestas. Cette double conception, l'une s'inscrivant dans une tradition morale médiévale, l'autre pétrie de droit romain, est à relier au parcours original de l'auteur. Né en 1500 à Andernach non loin de Cologne, Jacob Omphalius reçoit une éducation classique qui le mène ensuite à une longue peregrinatio academia à Cologne, Louvain, Paris et Toulouse, où il se frotte au droit romain et surtout au mos gallicus et où il entre en contact avec d'éminents humanistes, notamment Jean de Boyssoné, un proche d'Érasme. De retour à Cologne, il entre au service de l'archevêque de Cologne Hermann von Wied (1537-1547) en tant qu'assesseur au Reichskammergericht de Cologne, tandis que montent les tensions confessionnelles lors de la guerre de Smal-kalde, les résistances violentes de Cologne à la Réformation, suivie de la tentative de compromis de l'Intérim. Lui-même séduit, comme nombre d'humanistes, par la réforme luthérienne, il fait partie de ces défenseurs d'une " troisième voie ». Son De officio et potestate Principis, aux accents cicéroniens, se fait l'écho de ce choix médian qui échoue à trouver sa place dans l'Empire. La seconde partie du traité, consacrée à la définition juridique du pouvoir, délaisse, en effet, la légitimation théologique de l'autorité politique pour ne définir celle-ci que par rapport à la loi. Cette conception du pouvoir princier capable de résoudre les tensions des intérêts individuels et religieux en les réunissant sous une même sphère étatique, arrive trop tard après l'échec de l'Intérim, qui laisse place à une rethéologisation du débat politique dans les miroirs de prince. Annonciateur de l'œuvre de Bodin par son esquisse du caractère absolu de la souveraineté et de l'État comme garant de la paix religieuse, Omphalius proposait dans le contexte de la confessionnalisation de puiser dans l'Antiquité et notamment dans le droit romain une réponse aux conflits politicoreligieux. Cette analyse savante et percutante de l'œuvre du juriste colonais offre ainsi un nouvel éclairage sur l'humanisme allemand, trop souvent subordonné à la Réformation. On peut seulement regretter que l'auteur n'ait proposé, en annexe, une traduction complète de l'œuvre d'Omphalius, cette dernière n'ayant été que partiellement et parfois trop rapidement faite par T. Stammen et H.-O. Mühleisen.

Naïma GHERMANI (Université Pierre-Mendès-France - Grenoble II) 